\title{
Dideoxy Fingerprinting
}

National Cancer Institute

\section{Source}

National Cancer Institute. Dideoxy Fingerprinting. NCI Thesaurus. Code C19230.

A variation of SSCP analysis in which the DNA fragments are generated by chain terminating sequencing reactions. Can be more sensitive due to the increased number of fragments, only a small number of which might display an altered migration. 